\title{
Expression of LPA2 is associated with poor prognosis in human breast cancer and regulates HIF-1 $\alpha$ expression and breast cancer cell growth
}

\author{
MIN LI $^{1 *}$, DONG XIAO ${ }^{2}$, JIA ZHANG $^{1}$, HANGYING QU $^{3}$, YA YANG $^{4}$, YAN YAN $^{1}, \mathrm{XU} \mathrm{LIU}^{1}$, \\ JIZHAO WANG $^{1}$, LIN LIU $^{1}$, JIANSHENG WANG $^{1 *}$ and XIAOYI DUAN ${ }^{5 *}$
}

\begin{abstract}
${ }^{1}$ The Second Department of Thoracic Surgery, The First Affiliated Hospital of Xi'an Jiaotong University, Xi'an, Shaanxi 710061; ${ }^{2}$ Department of Surgical Oncology, The 3201 Hospital of Shaanxi Province, Hanzhong, Shaanxi 723000;

${ }^{3}$ The Second Affiliated Hospital of Shaanxi University of Chinese Medicine, Xianyang, Shaanxi 712000;

${ }^{4}$ Department III of Radiation Oncology, The First Affiliated Hospital of Zhengzhou University, Zhengzhou, Henan 450000;

${ }^{5}$ Department of Radiology, The First Affiliated Hospital of Xi'an Jiaotong University, Xi'an, Shaanxi 710061, P.R. China
\end{abstract}

Received May 3, 2016; Accepted June 11, 2016

DOI: $10.3892 / o r .2016 .5206$

\begin{abstract}
Breast cancer (BC) generally exhibits poor prognosis owing to its invasive and metastatic characteristics and is the leading cause of cancer-related deaths in women worldwide. Lysophosphatidic acid receptor 2 (LPA2) and hypoxia inducible factor- $1 \alpha$ (HIF-1 $\alpha)$ were found to be correlated with $\mathrm{BC}$ invasion and metastasis, respectively. However, the effect of LPA2 on BC in Chinese women has not yet been reported, nor have the overall survival and prognostic significance of LPA 2 or its association with HIF- $1 \alpha$ in BC. In the present study, we assessed the effect of LPA2 on HIF-1 $\alpha$ expression, on overall survival and prognostic significance in $\mathrm{BC}$ in Chinese women, and on cell proliferation, migration and invasion in MCF-7 BC cells in vitro. The data showed that LPA 2 and HIF-1 $\alpha$ protein expression levels were higher in the BC tissue specimens and that LPA2 expression was significantly associated with menopausal status (postmenopausal), nodal metastasis and tumor-node-metastasis (TNM) stage, whereas HIF-1 $\alpha$ expression was significantly associated with estrogen receptor status, nodal metastasis and TNM stage. Furthermore, LPA2 and HIF-1 $\alpha$ expression were positively
\end{abstract}

Correspondence to: Professor Xiaoyi Duan, Department of Radiology, The First Affiliated Hospital of Xi'an Jiaotong University, 277 West Yanta Road, Xi'an, Shaanxi 710061, P.R. China

E-mail: duanxy@mail.xjtu.edu.cn

Professor Jiansheng Wang, The Second Department of Thoracic Surgery, The First Affiliated Hospital of Xi'an Jiaotong University, 277 West Yanta Road, Xi'an, Shaanxi 710061, P.R. China

E-mail:wangjsh@mail.xjtu.edu.cn

${ }^{*}$ Contributed equally

Key words: breast cancer, lysophosphatidic acid receptor 2, hypoxia inducible factor- $1 \alpha$, survival, tumor cell growth correlated $(\mathrm{r}=0.562 ; \mathrm{P}<0.001)$. LPA 2 and HIF-1 $\alpha$ protein levels were associated with shorter overall patient survival according to univariate analysis (log-rank test; $\mathrm{P}<0.001$ ), and nodal metastasis, TNM stage, LPA2 and HIF-1 $\alpha$ expression were independent prognostic predictors in patients as determined by multivariate analysis $(\mathrm{P}<0.05)$. In vitro, the data suggested that LPA2 affected HIF-1 $\alpha$ expression and LPA2 overexpression or knockdown resulted in increased or inhibited tumor cell proliferation, migration and invasion, respectively. In conclusion, our data demonstrated that LPA2 expression was associated with HIF-1 $\alpha$ expression and that a high level of LPA2 was associated with shorter overall survival and was an independent prognostic predictor for $\mathrm{BC}$ in Chinese women. Furthermore, LPA2 showed the ability to regulate the cell proliferation, migration and invasion of BC cells.

\section{Introduction}

Cancer represents a major public health issue worldwide and constitutes an enormous burden on society $(1,2)$. Breast cancer (BC) is the most commonly diagnosed cancer and the leading cause of cancer-related deaths among women (3). Although current therapies have proven effective in reducing primary tumors, the 5-year survival rate of BC is still poor mainly due to its intensive tendency for invasion and metastasis (4). Thus, further study is needed to identify and evaluate biomarkers for prognostic prediction as well as to develop novel strategies for the prevention and control of $\mathrm{BC}$.

Lysophosphatidic acid (LPA) receptors are specific $G$ protein-coupled receptors that bind with lysophosphatidic acid to mediate a variety of biological processes such as cell proliferation, migration, invasion and differentiation (5). At least six LPA receptors (LPA1-6) have been identified (6). Notably, LPAs have been correlated with the invasive and metastatic behaviors of several malignant cancers including BC (7-9). LPA 2 is associated with a more malignant phenotype in carcinomas of the breast (10). The hypoxic microenvironment of a tumor also serves as an independent predictor of a poor 
prognosis in various types of cancer including BC (11); the effects of such hypoxia are mediated by the transcription factor hypoxia inducible factor- $1 \alpha$ (HIF-1 $\alpha)(12)$. Consistent with this, HIF-1 $\alpha$ is closely associated with the occurrence and progression of tumors (13-15), and HIF-1 $\alpha$ activation represents a final common event in the pathogenesis of different types of tumors $(12,16-18)$. Thus, HIF-1 $\alpha$ is considered to be specifically responsible for hypoxia-mediated progression of cancer $(19,20)$. However, the association between LPA2 and HIF-1 $\alpha$ in BC has not yet been described.

To address these issues, in the present study, we first detected the expression of LPA2 and HIF-1 $\alpha$ in BC tissue specimens to assess their association with patient clinicopathological and survival data. Subsequently, we assessed the role of LPA2 and HIF- $1 \alpha$ in BC in vitro and explored the effects of LPA 2 overexpression or knockdown on HIF-1 $\alpha$ expression and cell proliferation, migration and invasion.

\section{Materials and methods}

Tissue specimens. Tissue specimens from 156 patients with $\mathrm{BC}$ were collected from consecutive surgical cases at the Department of Surgical Oncology, the 3201st Hospital of Shaanxi Province, between 2005 and 2009. The histological type for all cases was breast ductal cancer. All tissues were pathologically examined. The patients were all females, ranging between the ages of 26 and 77 years. The clinicopathological data of the patients are documented in Table II. None of the 156 patients received neoadjuvant or adjuvant chemotherapy before surgery. The present study was approved by the Protection of Human Subjects Committee of the 3201st Hospital and complies with the Declaration of Helsinki.

Immunohistochemical (IHC) staining. Formalin-fixed paraffin-embedded tumor sections (5- $\mu$ m thickness) were analyzed by IHC staining using an anti-LPA 2 rabbit polyclonal antibody (ab38322), anti-HIF-1 $\alpha$ (ab82832) (1:200 dilution; Abcam, Cambridge, MA, USA), and a biotinconjugated secondary antibody. The staining was performed following the SP kit procedure (Golden Bridge International, Beijing, China). As a control, the primary antibody was replaced by phosphate-buffered saline (PBS). IHC staining results were independently assessed by two pathologists in a semi-quantitative manner, and graded in accordance with an immunoreactive score (IRS): IRS is equal to the percentage of positive cells ( 0 , negative; $1,<10 \% ; 2,10-50 \% ; 3,51-80 \%$; $4,>80 \%$ ) multiplied by the staining intensity (1, weak; 2, moderate; 3 , strong).

The scores ranged from 0 to 12 . A score of 6 or higher was considered high expression and below 6 was considered low expression. A score of 0 represented a negative staining result.

Cell culture. The non-tumorigenic MCF-10A and BC MCF-7 cell lines were obtained from the Cell Bank of Shanghai (Shanghai, China) and were cultured in Dulbecco's modified Eagle's medium (HyClone, Logan, UT, USA) supplemented with $10 \%$ heat-inactivated fetal bovine serum (Hzsjq Co. Ltd., Hangzhou, China) at $37^{\circ} \mathrm{C}$ in a humidified incubator under an atmosphere of $5 \%$ carbon dioxide. All experiments were performed with cells in the logarithmic phase of growth.
Plasmid and siRNA transfection. The plasmid (pENTR223LPA2) was obtained from the DNASU Plasmid Repository (Tempe, AZ, USA) and small interfering RNA (siRNA) molecules targeting human LPA2 (si-LPA2) were obtained from Santa Cruz Biotechnology (sc-39926; Santa Cruz, CA, USA). The MCF-7 cells were grown and transfected with the negative control (NC) (GenePharma Co., Ltd., Shanghai, China), pENTR223-LPA2 or si-LPA2 using Lipofectamine 2000 (Invitrogen, Carlsbad, CA, USA) according to the manufacturer's protocol. MCF-7 cells were cultured in normal medium as a control group (normal group).

Cell proliferation assessment. Following plasmid and siRNA transfection for $48 \mathrm{~h}$, the colorimetric 3-(4,5-dimethylthiazol2-yl)-2,5-diphenyltetrazolium bromide (MTT) assay was used to assess the proliferation of the MCF-7 cells. The MCF-7 cells $(100 \mu \mathrm{l})$ were seeded at a density of $4 \times 10^{4}$ cells/ $\mathrm{ml}$ in 96-well plates and were cultured for 24,48 and $72 \mathrm{~h}$. An aliquot of $10 \mu \mathrm{l}$ MTT solution in PBS $(5 \mathrm{mg} / \mathrm{ml})$ was added to each well and the plates were incubated for $4 \mathrm{~h}$ at $37^{\circ} \mathrm{C}$. Then, $150 \mu$ l dimethyl sulfoxide (Sigma, St. Louis, MO, USA) was added to each well and the plates were shaken for $15 \mathrm{~min}$ before reading the optical density of each well at $570 \mathrm{~nm}$ on a microplate reader. MCF-7 cells were cultured in normal medium as a control group. All experiments were conducted in triplicate.

Cell migration and invasion assays. Following plasmid and siRNA transfection for $48 \mathrm{~h}$, migration and invasion assays were conducted in MCF-7 cells using Transwell plates with $8-\mu \mathrm{m}$ pore size membranes (Millipore Inc., Billerica, MA, USA) as previously described (21). After incubation for $12 \mathrm{~h}$ (for migration assays) or $24 \mathrm{~h}$ (for invasion assays), cells remaining in the upper side of the filter were removed with cotton swabs. The cells attached on the lower surface were fixed, stained using crystal violet and washed with PBS. Cells were counted in 5-high power fields/membrane. The results are presented as the mean number of cells that migrated/field/membrane. MCF-7 cells were cultured in normal medium as a control group. All experiments were conducted in triplicate.

Western blot analyses. Following plasmid and siRNA transfection of MCF-7 cells for $48 \mathrm{~h}$, the proteins were extracted according to standard procedures of RIPA lysis buffer kit (Santa Cruz Biotechnology). Equal amounts of protein samples were separated onto a $10 \%$ sodium dodecyl sulfate-polyacrylamide gel using sodium dodecyl sulfate-polyacrylamide gel electrophoresis (SDS-PAGE) and were then transferred onto a polyvinylidene difluoride (PVDF) membrane (Millipore). The membranes were examined with the following specific primary antibodies: anti-LPA2 rabbit polyclonal or anti-HIF-1 $\alpha$ rabbit polyclonal (1:1,000 dilution) or anti- $\beta$-actin rabbit polyclonal antibodies (bs-0061R; 1:1,000 dilution) followed by the conjugated secondary antibody goat-anti-rabbit $\operatorname{IgG}(1: 3,000$ dilution) (both from Bioss, Woburn, MA, USA). The reactions were visualized using an enhanced chemiluminescence (ECL) reagent (Millipore). The band intensities of the western blotting were measured by densitometry using Quantity One software (Bio-Rad Laboratories, Hercules, CA, USA). MCF-7 cells were cultured in normal medium as a control group 

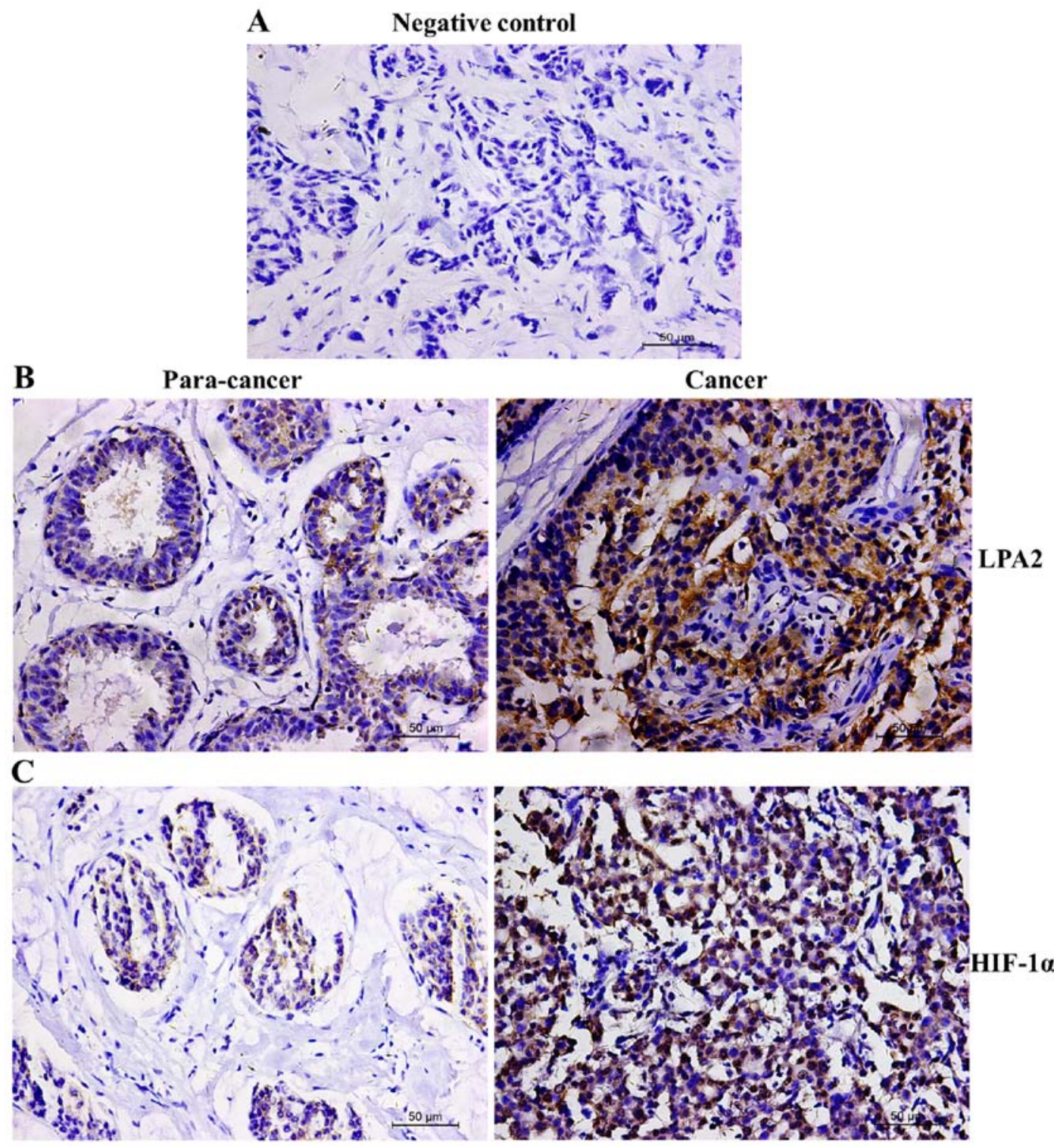

Figure 1. Immunohistochemical analysis of LPA2 and HIF-1 $\alpha$ expression in the breast cancer (BC) tissue specimens. (A) Negative staining of LPA2 and HIF-1 $\alpha$ proteins in BC tissue specimens. (B) LPA2 expression in para-cancer and BC tissue specimens. LPA2 staining is localized predominantly in the cell membrane and cytoplasm. (C) HIF-1 $\alpha$ expression in para-cancer and BC tissue specimens. HIF-1 $\alpha$ staining is localized predominantly in the nuclei. Scale bar, $50 \mu \mathrm{m}$.

(normal group). The protein levels were normalized to those of $\beta$-actin protein level used as a loading control.

Statistical analysis. The Chi-square test was used to analyze the association of LPA2 and HIF-1 $\alpha$ expression with the clinicopathological variables. The Spearman's rank correlation coefficient test was performed to associate LPA2 expression with HIF-1 $\alpha$ expression in tissue specimens. Overall survival was defined as the time from the date of surgery to the date of the last follow-up or of patient death. Survival curves were calculated using the Kaplan-Meier method and compared using the log-rank test. Multivariate analysis using Cox's proportional hazard model was used to assess prognostic factors. The Student's t-test or one-way ANOVA was used to compare normally distributed variables. $\mathrm{P}<0.05$ was considered significant. All analyses were performed using SPSS software version 18.0 (IBM Corp., New York, NY, USA).

\section{Results}

Differential LPA2 and HIF-1 $\alpha$ protein expression is associated with the clinicopathological data of the patients with $B C$. We first assessed the protein expression of LPA2 and HIF-1 $\alpha$ using IHC in 156 BC tissue specimens (Fig. 1A as a negative control) and found that the LPA2 protein was localized in both the cell membrane and cytoplasm (Fig. 1B) whereas the HIF-1 $\alpha$ protein was predominantly localized in the nuclei (Fig. 1C). The expression levels of these two proteins significantly differed between the cancer and paracancer normal tissues (Table I). High expression of the LPA2 protein was significantly associated with menopausal status, nodal metastasis and TNM stage, yet not with age, tumor site, tumor diameter, estrogen or progesterone receptor and Her-2 status, and histologic grade (Table II). In comparison, HIF-1 $\alpha$ expression was associated with estrogen receptor status, nodal 
Table I. Differential expression of LPA2 and HIF-1 $\alpha$ proteins in breast cancer (BC) tissues vs. para-cancer normal tissues.

\begin{tabular}{|c|c|c|c|c|c|c|}
\hline & \multicolumn{2}{|c|}{ LPA2 } & \multirow[b]{2}{*}{ P-value } & \multicolumn{2}{|c|}{ HIF- $1 \alpha$} & \multirow[b]{2}{*}{ P-value } \\
\hline & + & - & & + & - & \\
\hline Cancer & 110 & 46 & & 116 & 40 & \\
\hline Para-carcinoma & 30 & 126 & $<0.001$ & 33 & 123 & $<0.001$ \\
\hline Total & 140 & 172 & & 149 & 163 & \\
\hline
\end{tabular}

$\mathrm{BC}$, breast cancer; LPA2, lysophosphatidic acid receptor 2; HIF-1 $\alpha$, hypoxia inducible factor-1 $\alpha$.

Table II. Association of LPA2 and HIF-1 $\alpha$ expression with clinicopathological data from the BC patients.

\begin{tabular}{|c|c|c|c|c|c|c|c|}
\hline \multirow[b]{2}{*}{ Variable } & \multirow[b]{2}{*}{$\mathrm{N}$} & \multicolumn{2}{|c|}{ LPA2 } & \multirow[b]{2}{*}{ P-value } & \multicolumn{2}{|c|}{ HIF- $1 \alpha$} & \multirow[b]{2}{*}{ P-value } \\
\hline & & High & Low & & High & Low & \\
\hline \multicolumn{8}{|l|}{ Age (years) } \\
\hline$<50$ & 79 & 48 & 31 & & 40 & 39 & \\
\hline$\geq 50$ & 77 & 43 & 34 & 0.534 & 43 & 34 & 0.514 \\
\hline \multicolumn{8}{|l|}{ Menopausal status } \\
\hline Premenopausal & 63 & 29 & 34 & & 31 & 32 & \\
\hline Postmenopausal & 93 & 62 & 31 & 0.010 & 52 & 41 & 0.410 \\
\hline \multicolumn{8}{|l|}{ Tumor site } \\
\hline Left & 87 & 51 & 36 & & 46 & 41 & \\
\hline Right & 69 & 40 & 29 & 0.935 & 37 & 32 & 0.926 \\
\hline \multicolumn{8}{|c|}{ Tumor diameter $(\mathrm{cm})$} \\
\hline$\leq 2$ & 41 & 19 & 22 & & 21 & 20 & \\
\hline$>2$ to $\leq 5$ & 98 & 63 & 35 & & 51 & 47 & \\
\hline$>5$ & 17 & 9 & 8 & 0.131 & 11 & 6 & 0.600 \\
\hline \multicolumn{8}{|l|}{ ER status } \\
\hline Negative & 70 & 42 & 28 & & 45 & 25 & \\
\hline Positive & 86 & 49 & 37 & 0.703 & 38 & 48 & 0.012 \\
\hline \multicolumn{8}{|l|}{ PR status } \\
\hline Negative & 70 & 40 & 30 & & 36 & 34 & \\
\hline Positive & 86 & 51 & 35 & 0.786 & 47 & 39 & 0.688 \\
\hline \multicolumn{8}{|l|}{ Her-2 status } \\
\hline Negative & 111 & 66 & 45 & & 60 & 51 & \\
\hline Positive & 45 & 25 & 20 & 0.654 & 23 & 22 & 0.739 \\
\hline \multicolumn{8}{|l|}{ Nodal metastasis } \\
\hline Negative & 50 & 22 & 28 & & 12 & 38 & \\
\hline Positive & 106 & 69 & 37 & 0.013 & 71 & 35 & $<0.001$ \\
\hline \multicolumn{8}{|l|}{ Histologic grade } \\
\hline 1 & 32 & 21 & 11 & & 14 & 18 & \\
\hline 2 & 78 & 40 & 38 & & 39 & 39 & \\
\hline 3 & 46 & 30 & 16 & 0.203 & 30 & 16 & 0.126 \\
\hline \multicolumn{8}{|l|}{ TNM stage } \\
\hline I & 23 & 9 & 14 & & 8 & 15 & \\
\hline II & 60 & 32 & 28 & & 28 & 32 & \\
\hline III & 48 & 30 & 18 & & 26 & 22 & \\
\hline IV & 25 & 20 & 5 & 0.026 & 21 & 4 & 0.003 \\
\hline
\end{tabular}

ER, estrogen receptor; PR, progesterone receptor; Her-2, human epidermal growth factor receptor-2; TNM, tumor-node-metastasis. 
Table III. Association of LPA2 and HIF- $1 \alpha$ expression.

\begin{tabular}{lllcll}
\hline & \multicolumn{2}{c}{ LPA2 } & & \\
\cline { 2 - 3 } & High & Low & & r & P-value \\
\hline HIF-1 $\alpha$ & & & & \\
High & 70 & 13 & & \\
Low & 21 & 52 & 0.562 & $<0.001$ \\
\hline
\end{tabular}

LPA2, lysophosphatidic acid receptor 2; HIF-1 $\alpha$, hypoxia inducible factor-1 $1 \alpha$.
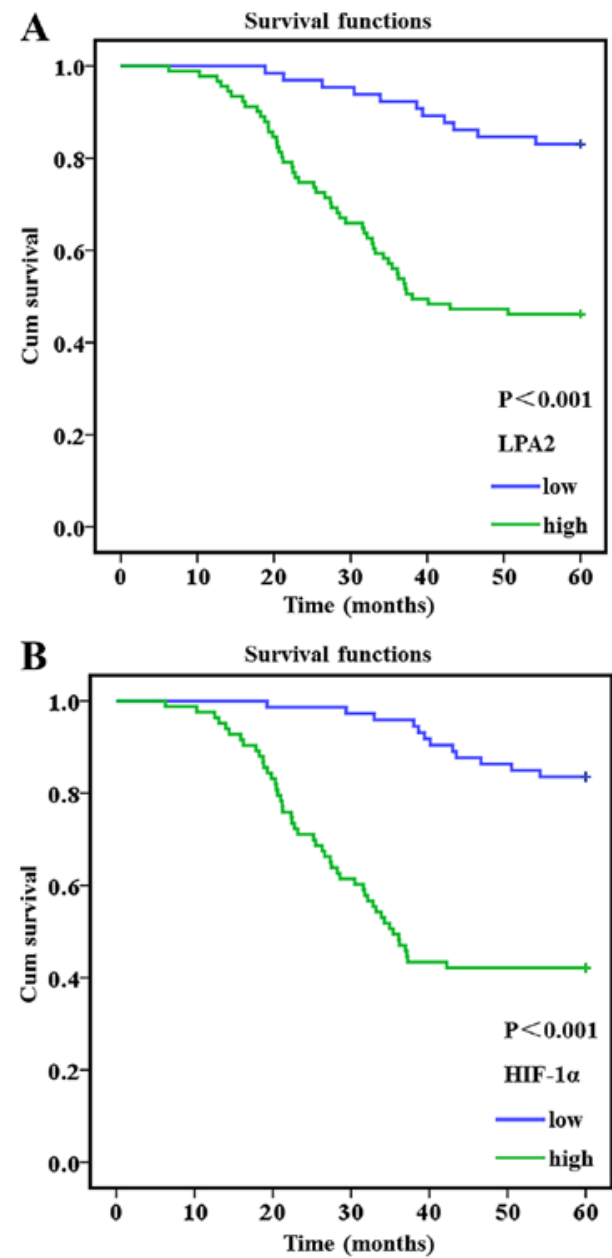

Figure 2. Kaplan-Meier curves of the patients with breast cancer (BC) stratified by LPA2 and HIF-1 $\alpha$ expression. Cumulative overall survival differences between patients with high and low expression of these two proteins. Patients with high protein expression levels showed a poorer overall survival using the log-rank test. (A) LPA2 $\left({ }^{* * *} \mathrm{P}<0.001\right)$. (B) HIF-1 $\left.\alpha{ }^{(* * *} \mathrm{P}<0.001\right)$.

metastasis and TNM stage, but not with age, menopausal status, tumor site, tumor diameter, progesterone receptor and Her-2 status and grade. In addition, LPA2 expression was associated with HIF-1 $\alpha$ expression in the BC tissues. Specifically, Spearman's rank correlation coefficient test showed that there were 91 cancer cases expressing a high level of LPA2 vs. 83 cases with HIF- $1 \alpha$ expression (Table III), revealing a positive association $(\mathrm{r}=0.562 ; \mathrm{P}<0.001)$.
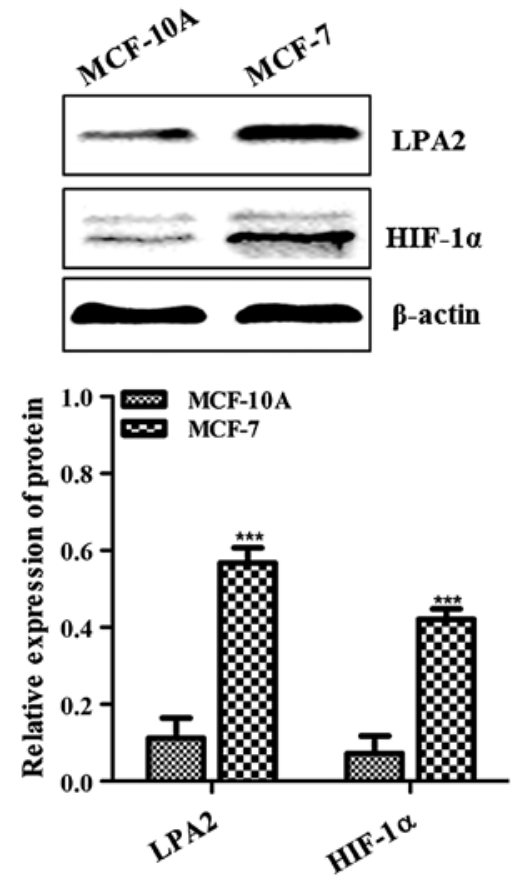

Figure 3. LPA2 and HIF-1 $\alpha$ expression in MCF-10A and MCF-7 cell lines. Western blot analyses of the expression levels of LPA2 and HIF-1 $\alpha$ in MCF-7 $\mathrm{BC}$ vs. MCF-10A non-tumorigenic cells $\left({ }^{* * * *} \mathrm{P}<0.001\right)$.

Association of LPA2 and HIF-1 $\alpha$ expression with the survival of patients with $B C$. The Kaplan-Meier curves and the log-rank test data showed that patients with a high LPA2-expressing tumor had a statistically significantly poorer overall survival compared to those with a low LPA2-expressing tumor (Fig. 2A and Table IV) of 41 months [95\% confidence interval (CI), 38.053-45.531] vs. 55 months (95\% CI, 53.497-58.356; $\mathrm{P}<0.001$ ). The same was true for HIF-1 $\alpha$ expression (Fig. 2B and Table IV). Furthermore, tumor diameter, nodal metastasis and TNM stage were all associated with poor overall patient survival $(\mathrm{P}<0.05)$. The multivariate $\mathrm{Cox}$ regression model showed that nodal metastasis $[\mathrm{P}=0.007$, hazard ratio $(\mathrm{HR})=7.516,95 \% \mathrm{CI}, 1.748-32.327]$, TNM stage $(\mathrm{P}<0.001$, $\mathrm{HR}=2.436,95 \% \mathrm{CI}, 1.703-3.486)$, LPA2 expression $(\mathrm{P}=0.036$ $\mathrm{HR}=2.294,95 \% \mathrm{CI}, 1.054-4.992)$ and HIF-1 $\alpha(\mathrm{P}=0.029$, $\mathrm{HR}=2.369,95 \% \mathrm{CI}, 1.090-5.150$ ) were independent prognostic indicators for the survival of patients with $\mathrm{BC}$ (Table V).

LPA2 and HIF-1 $\alpha$ are expressed in human BC cell lines. Our ex vivo data demonstrated that LPA2 and HIF-1 $\alpha$ protein expression were positively correlated $(\mathrm{r}=0.562)$ and were associated with a poor overall survival; however, this result had not previously been reported with regard to both LPA2 and HIF- $1 \alpha$ in BC. Therefore, we further assessed the role of LPA2 and HIF-1 $\alpha$ in a human BC cell line. We first explored the expression levels of LPA2 and HIF-1 $\alpha$ in non-tumorigenic MCF-10A and MCF-7 BC cells. As shown in Fig. 3, the levels of both LPA2 and HIF-1 $\alpha$ were high in MCF-7 and low in MCF-10A as assessed by western blot analysis; this difference was statistically significant $(\mathrm{P}<0.001)$.

Effects of LPA2 overexpression in BC cells. At $48 \mathrm{~h}$ following transfection of MCF-7 cells with the plasmid 
Table IV. Univariate analysis of overall survival.

\begin{tabular}{|c|c|c|c|c|}
\hline \multirow[b]{2}{*}{ Variable } & \multirow[b]{2}{*}{$\mathrm{N}$} & \multicolumn{2}{|c|}{ Overall survival } & \multirow[b]{2}{*}{ P-value } \\
\hline & & Median & $95 \% \mathrm{CI}$ & \\
\hline \multicolumn{5}{|l|}{ LPA2 } \\
\hline High & 91 & $41.00 \pm 1.908$ & $38.053-45.531$ & \\
\hline Low & 65 & $55.00 \pm 1.239$ & $53.497-58.356$ & $<0.001$ \\
\hline \multicolumn{5}{|l|}{ HIF- $1 \alpha$} \\
\hline High & 83 & $39.00 \pm 2.017$ & $35.839-43.746$ & \\
\hline Low & 73 & $56.00 \pm 0.981$ & $54.728-58.575$ & $<0.001$ \\
\hline \multicolumn{5}{|l|}{ Age (years) } \\
\hline$<50$ & 79 & $47.00 \pm 1.891$ & $44.052-51.465$ & \\
\hline$\geq 50$ & 77 & $47.00 \pm 1.921$ & $43.837-51.368$ & 0.920 \\
\hline \multicolumn{5}{|l|}{ Menopausal status } \\
\hline Premenopausal & 63 & $49.00 \pm 2.128$ & $45.431-53.771$ & \\
\hline Postmenopausal & 93 & $46.00 \pm 1.729$ & 42.993-49.769 & 0.123 \\
\hline \multicolumn{5}{|l|}{ Tumor site } \\
\hline Left & 87 & $48.00 \pm 1.725$ & $44.981-51.742$ & \\
\hline Right & 69 & $46.00 \pm 2.130$ & $42.650-50.999$ & 0.597 \\
\hline \multicolumn{5}{|c|}{ Tumor diameter $(\mathrm{cm})$} \\
\hline$\leq 2$ & 41 & $54.00 \pm 1.860$ & $51.191-58.480$ & \\
\hline$>2$ to $\leq 5$ & 98 & $45.00 \pm 1.776$ & $41.581-48.544$ & \\
\hline$>5$ & 17 & $45.00 \pm 4.257$ & $37.182-53.869$ & 0.007 \\
\hline \multicolumn{5}{|l|}{ ER status } \\
\hline Negative & 70 & $46.00 \pm 2.193$ & $42.581-51.179$ & \\
\hline Positive & 86 & $48.00 \pm 1.667$ & $45.067-51.601$ & 0.978 \\
\hline \multicolumn{5}{|l|}{ PR status } \\
\hline Negative & 70 & $48.00 \pm 1.986$ & 44.959-52.746 & \\
\hline Positive & 86 & $46.00 \pm 1.827$ & $43.148-50.310$ & 0.363 \\
\hline \multicolumn{5}{|l|}{ Her-2 status } \\
\hline Negative & 111 & $46.00 \pm 1.627$ & $43.092-49.468$ & \\
\hline Positive & 45 & $51.00 \pm 2.314$ & $46.603-55.674$ & 0.111 \\
\hline \multicolumn{5}{|l|}{ Nodal metastasis } \\
\hline Negative & 50 & $58.00 \pm 1.053$ & $56.544-60.672$ & \\
\hline Positive & 106 & $42.00 \pm 1.704$ & $39.187-45.868$ & $<0.001$ \\
\hline \multicolumn{5}{|l|}{ Histologic grade } \\
\hline 1 & 32 & $53.00 \pm 2.569$ & 48.704-58.775 & \\
\hline 2 & 78 & $45.00 \pm 2.004$ & $41.984-49.840$ & \\
\hline 3 & 46 & $46.00 \pm 2.333$ & $41.895-51.041$ & 0.057 \\
\hline \multicolumn{5}{|l|}{ TNM stage } \\
\hline I & 23 & $58.00 \pm 1.157$ & $56.550-61.084$ & \\
\hline II & 60 & $53.00 \pm 1.869$ & $49.397-56.723$ & \\
\hline III & 48 & $45.00 \pm 2.320$ & $40.795-49.888$ & \\
\hline IV & 25 & $29.00 \pm 2.819$ & $23.496-34.547$ & $<0.001$ \\
\hline
\end{tabular}

CI, confidence interval; LPA2, lysophosphatidic acid receptor 2; HIF-1 $\alpha$, hypoxia inducible factor-1 $\alpha$; ER, estrogen receptor; PR, progesterone receptor; Her-2, human epidermal growth factor receptor-2; TNM, tumor-node-metastasis.

(pENTR223-LPA2), western blot analysis showed that LPA2 protein was overexpressed in the LPA2-overexpressing cells compared to that in the normal and $\mathrm{NC}$ group (control groups) ( $\mathrm{P}<0.001$; Fig. 4A). Upon LPA2 overexpression, the level of HIF-1 $\alpha$ was elevated in the MCF-7 cells compared to that in the controls $(\mathrm{P}<0.05$; Fig. $4 \mathrm{~A})$. The MTT assay showed 
Table V. Multivariate Cox proportional hazard analysis of overall survival.

\begin{tabular}{lccc}
\hline & \multicolumn{2}{c}{ Overall survival } & \\
\cline { 2 - 3 } Variable & HR & $95 \%$ CI & P-value \\
\hline Age (years) & 1.389 & $0.755-2.556$ & 0.290 \\
Menopausal status & 1.281 & $0.651-2.520$ & 0.473 \\
Tumor site & 0.962 & $0.555-1.667$ & 0.890 \\
Tumor diameter $(\mathrm{cm})$ & 1.381 & $0.850-2.242$ & 0.192 \\
ER status & 0.931 & $0.528-1.642$ & 0.805 \\
PR status & 1.288 & $0.753-2.201$ & 0.355 \\
Her-2 status & 0.697 & $0.341-1.426$ & 0.323 \\
Nodal metastasis & 7.516 & $1.748-32.327$ & 0.007 \\
Grade & 0.803 & $0.535-1.207$ & 0.292 \\
TNM stage & 2.436 & $1.703-3.486$ & 0.000 \\
LPA2 & 2.294 & $1.054-4.992$ & 0.036 \\
HIF-1 $\alpha$ & 2.369 & $1.090-5.150$ & 0.029 \\
\hline
\end{tabular}

HR, hazard ratio; CI, confidence interval; ER, estrogen receptor; PR, progesterone receptor; Her-2, human epidermal growth factor receptor-2; TNM, tumor-node-metastasis; LPA2, lysophosphatidic acid receptor 2 ; HIF-1 $\alpha$, hypoxia inducible factor- $1 \alpha$.

that overexpression of LPA2 promoted the proliferation of MCF-7 cells in a time-dependent manner $(\mathrm{P}<0.01$ at $72 \mathrm{~h}$; Fig. 4B). To further analyze the effect of LPA 2 overexpression on MCF-7 cells, cell migration and invasion assays were conducted, demonstrating that these characteristics of MCF-7 cells were enhanced following LPA2 overexpression $(\mathrm{P}<0.001$; Fig. 4C and D).

Effects of LPA2 knockdown on BC cells. The effects of LPA2 knockdown were directly inverse to those of its upregulation. At $48 \mathrm{~h}$ following transfection of MCF-7 cells with si-LPA2, both LPA2 ( $\mathrm{P}<0.001$; Fig. 5A) and HIF-1 $\alpha(\mathrm{P}<0.05$; Fig. 5A) expression was downregulated compared to the controls as assessed by western blot analysis. Similarly, MCF-7 cell proliferation was inhibited in a time-dependent manner $(\mathrm{P}<0.05$ at 72 h; Fig. 5B) and their migration and invasion were reduced following LPA2 downregulation $(\mathrm{P}<0.001$ and $\mathrm{P}<0.01$; Fig. 5C and D).

\section{Discussion}

The invasive and metastatic properties of breast cancer (BC) play a considerable role in its poor prognosis, requiring the development of novel strategies to combat its position as the leading cause of cancer-related deaths among women worldwide. The results of the present study illustrated the role of LPA2 in the regulation of HIF- $1 \alpha$ expression and BC progression, suggesting its potential for $\mathrm{BC}$ diagnostic and therapeutic application to help facilitate the prevention and control of this disease.

LPA receptors are specific $G$ protein-coupled receptors and multifunctional signaling molecules that control the proliferation, motility, and differentiation of many cell types including cancer cells $(5,22)$. Although the expression and functions of LPA2 have been the subject of only a few studies, increased LPA2 expression has been reported in invasive BC $(10,23)$. However, the study of the roles of LPA2 in BC has mainly focused on western populations; in contrast, data related to the effect of LPA2 on BC in Chinese women or to the overall survival and prognostic significance of LPA2 in $\mathrm{BC}$ are not available. In the present study, we first analyzed the association of LPA2 expression in BC tissue specimens with the clinicopathological and survival data of Chinese women. Our date showed that LPA2 was more highly expressed in BC tissues than in para-cancer tissues, consistent with some prior reports from other populations $(8,10)$. We also found that LPA2 was upregulated more frequently in postmenopausal than in premenopausal women, suggesting that LPA2 overexpression was more strongly related to the carcinogenesis of postmenopausal BC, consistent with the study by Kitayama et al (10). In addition, our data showed that LPA2 overexpression was significantly associated with nodal metastasis and later clinical TNM stage and that patients with high LPA2-expressing tumors had a statistically significant poorer overall survival compared to those with tumors expressing low levels of LPA2. These results confirmed the validity of LPA2 as an independent prognostic indicator for patient survival in $\mathrm{BC}$.

HIF-1 $\alpha$ has a close association with tumor occurrence and progression and its activation represents a final common event in the pathogenesis of multiple tumor types $(12,18,24-27)$. Data from the present study showed that BC tumors exhibiting high HIF-1 $\alpha$ expression correlated with statistically significant poorer overall patient survival compared to those with low levels of HIF-1 $\alpha$ expression, which is consistent with other studies (28). The association between LPA2 and HIF-1 $\alpha$ had not been previously reported; however, the results of the present study indicated that a high level of LPA2 expression was associated with a high level of HIF-1 $\alpha$ expression in BC clinical tissue specimens, revealing a positive association $(r=0.562, P<0.001)$. This suggested the existence of a potential gene regulatory effect between LPA2 and HIF-1 $\alpha$. In the present study we aimed to explore whether LPA2 was able to regulate $\mathrm{HIF}-1 \alpha$ in $\mathrm{BC}$ cells.

To address this issue, we performed in vitro experiments to assess the effect of LPA2 on HIF-1 $\alpha$ expression in the MCF-7 $\mathrm{BC}$ cell line. Consistent with an earlier study, we found that both LPA2 and HIF-1 $\alpha$ exhibited higher expression (MCF-7) than non-tumorigenic breast (MCF-10A) cells $(8,29)$. In addition, we found when the level of LPA2 was artificially increased through exogenous overexpression, the level of HIF-1 $\alpha$ was concurrently elevated compared to MCF-7 controls $(\mathrm{P}<0.05)$ and the proliferation $(\mathrm{P}<0.01)$, migration and invasion of MCF-7 cells $(\mathrm{P}<0.001)$ was enhanced. Conversely, we also found when the level of LPA2 was decreased via siRNA knockdown, HIF-1 $\alpha$ also exhibited low expression compared to MCF-7 controls $(\mathrm{P}<0.05)$ and that $\mathrm{MCF}-7$ proliferation $(\mathrm{P}<0.05)$, migration $(\mathrm{P}<0.001)$ and invasion $(\mathrm{P}<0.01)$ were also inhibited. Together, these data indicated that LPA2 was able to regulate HIF-1 $\alpha$ expression and the proliferation, migration and invasion of BC cells.

In summary, the present study demonstrated that LPA2 was able to serve as an independent prognostic indicator for 

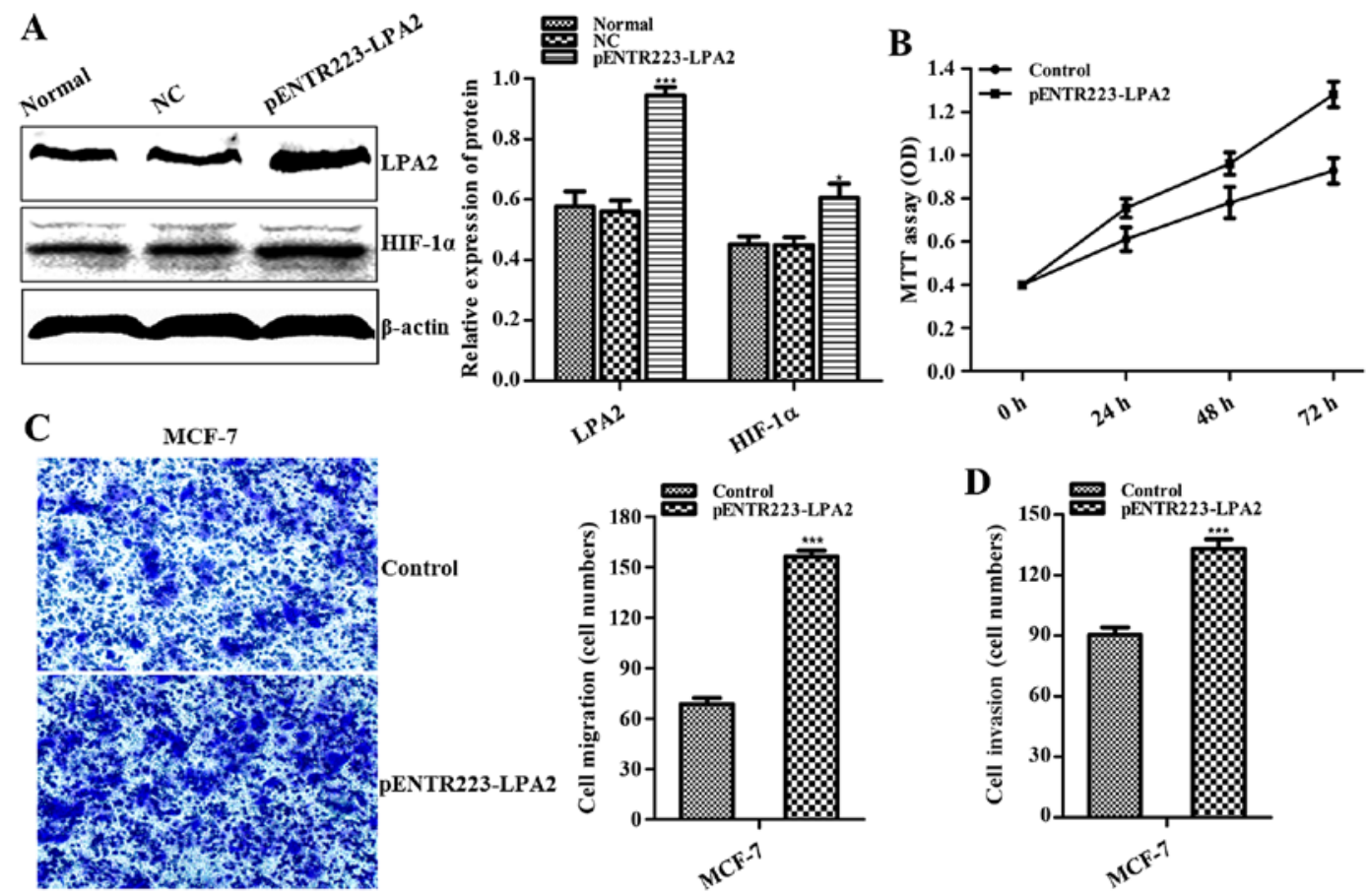

Figure 4. Effects of LPA2 overexpression on breast cancer cells. (A) Western blot analyses of LPA2 expression in the pENTR223-LPA2 group compared to the normal and NC groups $\left({ }^{* * *} \mathrm{P}<0.001\right)$ and HIF-1 $\alpha$ expression levels in LPA2-overexpressing cells compared to the normal and NC groups ("P<0.05). (B) MTT assay showing the growth of MCF-7 cells in the pENTR223-LPA2 group at $72 \mathrm{~h}\left({ }^{* *} \mathrm{P}<0.01\right)$. (C and D) Transwell assays showing the migration and invasion of MCF-7 cells in the pENTR223-LPA2 group compared to the controls $\left({ }^{* * * *} \mathrm{P}<0.001\right)$.
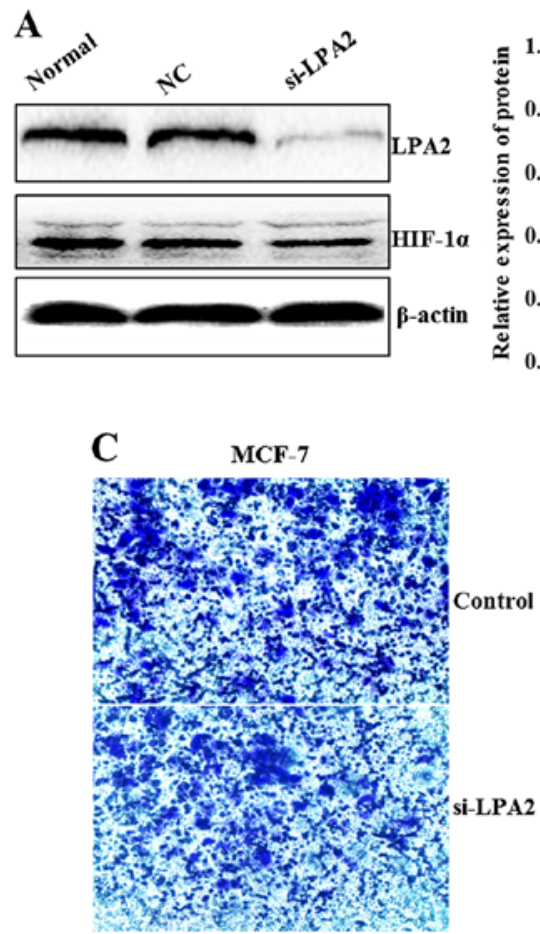
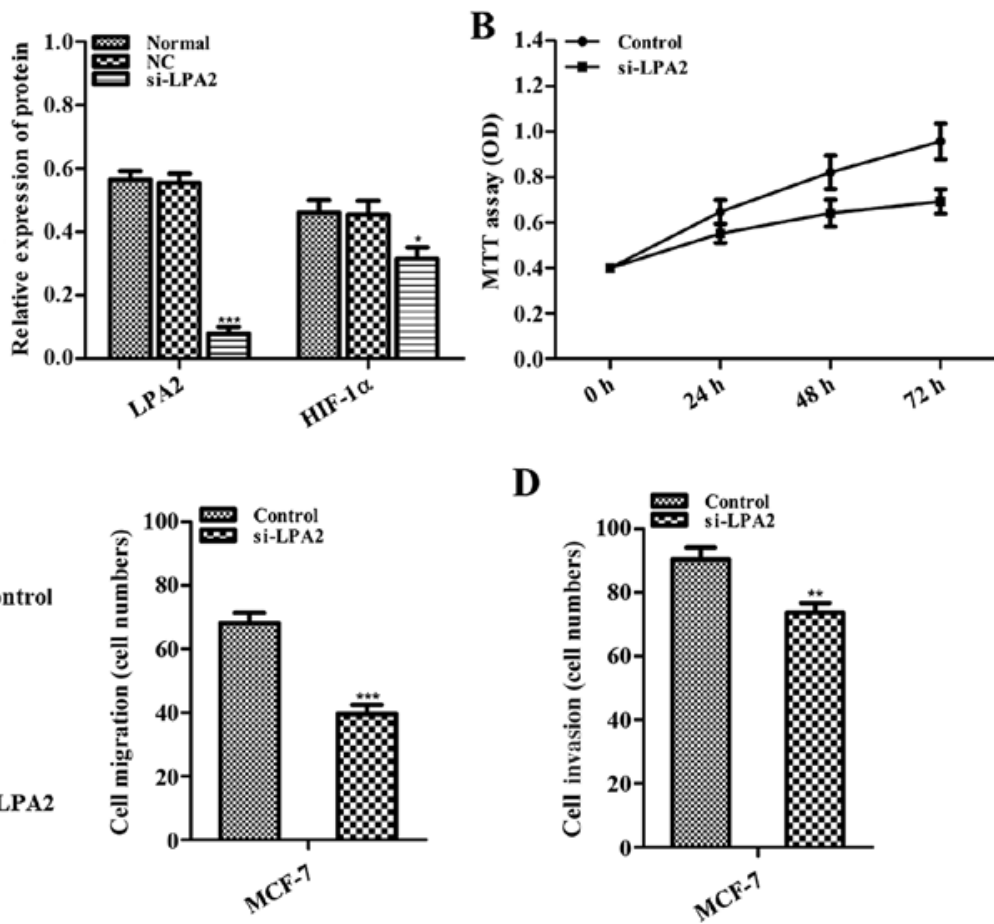

D

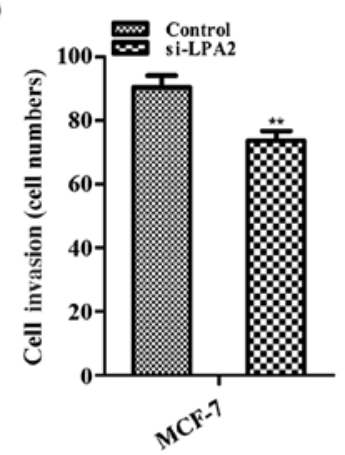

Figure 5. Effects of LPA2 knockdown on breast cancer cells. (A) Western blot analyses showing LPA2 expression in the si-LPA2 group compared to the normol and $\mathrm{NC}$ groups $\left({ }^{* * *} \mathrm{P}<0.001\right)$ and $\mathrm{HIF}-1 \alpha$ expression in $\mathrm{MCF}-7$ cells with reduced LPA2 levels compared to the normal and NC groups $\left({ }^{*} \mathrm{P}<0.05\right)$. (B) MTT assay showing the growth of MCF-7 cells in the si-LPA2 group at $72 \mathrm{~h}$ compared to the controls ("P<0.05). (C and D) Transwell assays showing the migration $\left({ }^{* * *} \mathrm{P}<0.001\right)$ and invasion $\left({ }^{* *} \mathrm{P}<0.01\right)$ of $\mathrm{MCF}-7$ cells in the si-LPA2 group compared to controls.

survival in BC and that high LPA2 expression was associated with poor overall patient survival among Chinese women. LPA2 and HIF-1 $\alpha$ protein expression exhibited a positive association, and LPA2 showed the ability to regulate HIF-1 $\alpha$ expression and proliferation, migration and invasion in $\mathrm{BC}$ cells. Thus, our data suggest that LPA2 may function as a 
useful prognostic marker of $\mathrm{BC}$ and may also represent a valid therapeutic target for $\mathrm{BC}$ management.

\section{Acknowledgements}

The present study was supported by a grant from the National Natural Science Foundation of China (no. 81471710).

\section{References}

1. Siegel RL, Miller KD and Jemal A: Cancer statistics, 2015. CA Cancer J Clin 65: 5-29, 2015.

2. Long J, Luo GP, Xiao ZW, Liu ZQ, Guo M, Liu L, Liu C, Xu J, Gao YT, Zheng Y, et al: Cancer statistics: Current diagnosis and treatment of pancreatic cancer in Shanghai, China. Cancer Lett 346: 273-277, 2014.

3. Torre LA, Bray F, Siegel RL, Ferlay J, Lortet-Tieulent J and Jemal A: Global cancer statistics, 2012. CA Cancer J Clin 65 87-108, 2015

4. Petekkaya I, Ayyildiz V, Kizilarslanoglu MC, Sahin U, Gezgen G, Roach EC, Karcaaltincaba M and Altundag K: Prognosis of breast cancer in patients with peritoneal metastasis. Breast 21: 420-421, 2012

5. Gotoh M, Fujiwara Y, Yue J, Liu J, Lee S, Fells J, Uchiyama A, Murakami-Murofushi K, Kennel S, Wall J, et al: Controlling cancer through the autotaxin-lysophosphatidic acid receptor axis. Biochem Soc Trans 40: 31-36, 2012.

6. Chun J, Hla T, Lynch KR, Spiegel S and Moolenaar WH: International Union of Basic and Clinical Pharmacology. LXXVIII. Lysophospholipid receptor nomenclature. Pharmaco Rev 62: 579-587, 2010.

7. Sedláková I, Vávrová J, Tošner J and Hanousek L: Lysophosphatidic acid (LPA) - a perspective marker in ovarian cancer. Tumour Biol 32: 311-316, 2011.

8. Sun K, Cai H, Duan X, Yang Y, Li M, Qu J, Zhang X and Wang J: Aberrant expression and potential therapeutic target of lysophosphatidic acid receptor 3 in triple-negative breast cancers. Clin Exp Med 15: 371-380, 2015.

9. Sun K, Duan X, Cai H, Liu X, Yang Y, Li M, Zhang X and Wang J: Curcumin inhibits LPA-induced invasion by attenuating RhoA/ROCK/MMPs pathway in MCF7 breast cancer cells. Clin Exp Med 16: 37-47, 2016.

10. Kitayama J, Shida D, Sako A, Ishikawa M, Hama K, Aoki J, Arai $\mathrm{H}$ and Nagawa $\mathrm{H}$ : Over-expression of lysophosphatidic acid receptor-2 in human invasive ductal carcinoma. Breast Cancer Res 6: R640-R646, 2004

11. Bos R, van der Groep P, Greijer AE, Shvarts A, Meijer S, Pinedo HM, Semenza GL, van Diest PJ and van der Wall E: Levels of hypoxia-inducible factor-1alpha independently predict prognosis in patients with lymph node negative breast carcinoma. Cancer 97: 1573-1581, 2003.

12. Semenza GL: Targeting HIF-1 for cancer therapy. Nat Rev Cancer 3: 721-732, 2003.
13. Span PN and Bussink J: Biology of hypoxia. Semin Nucl Med 45: 101-109, 2015.

14. Fransén K, Fenech M, Fredrikson M, Dabrosin C and Söderkvist P: Association between ulcerative growth and hypoxia inducible factor-1alpha polymorphisms in colorectal cancer patients. Mol Carcinog 45: 833-840, 2006.

15. Putra AC,TanimotoK, Arifin Mand HiyamaK: Hypoxia-inducible factor-1 $\alpha$ polymorphisms are associated with genetic aberrations in lung cancer. Respirology 16: 796-802, 2011.

16. Amelio I and Melino G: The 'Sharp' blade against HIF-mediated metastasis. Cell Cycle 11: 4530-4535, 2012.

17. Piccolo S, Enzo E and Montagner M: p63, Sharp1, and HIFs: Master regulators of metastasis in triple-negative breast cancer. Cancer Res 73: 4978-4981, 2013.

18. Ke Q and Costa M: Hypoxia-inducible factor-1 (HIF-1). Mol Pharmacol 70: 1469-1480, 2006

19. Bernaudin M, Tang Y, Reilly M, Petit E and Sharp FR: Brain genomic response following hypoxia and re-oxygenation in the neonatal rat. Identification of genes that may contribute to hypoxia-induced ischemic tolerance. J Biol Chem 277: 39728-39738, 2002.

20. Badowska-Kozakiewicz AM, Budzik MP and Przybylski J: Hypoxia in breast cancer. Pol J Pathol 66: 337-346, 2015.

21. Huanna T, Tao Z, Xiangfei W, Longfei A, Yuanyuan X, Jianhua W, Cuifang Z, Manjing J, Wenjing C, Shaochuan Q, et al: GALNT14 mediates tumor invasion and migration in breast cancer cell MCF-7. Mol Carcinog 54: 1159-1171, 2015.

22. Choi JW, Herr DR, Noguchi K, Yung YC, Lee CW, Mutoh T, Lin ME, Teo ST, Park KE, Mosley AN, et al: LPA receptors: Subtypes and biological actions. Annu Rev Pharmacol Toxicol 50: 157-186, 2010.

23. Liu S, Umezu-Goto M, Murph M, Lu Y, Liu W, Zhang F, Yu S, Stephens LC, Cui X, Murrow G, et al: Expression of autotaxin and lysophosphatidic acid receptors increases mammary tumorigenesis, invasion, and metastases. Cancer Cell 15: 539-550, 2009.

24. Lee JW, Bae SH, Jeong JW, Kim SH and Kim KW: Hypoxia-inducible factor (HIF-1) $\alpha$ : Its protein stability and biological functions. Exp Mol Med 36: 1-12, 2004.

25. Birner P, Gatterbauer B, Oberhuber G, Schindl M, Rössler K, Prodinger A, Budka H and Hainfellner JA: Expression of hypoxiainducible factor-1 alpha in oligodendrogliomas: Its impact on prognosis and on neoangiogenesis. Cancer 92: 165-171, 2001.

26. Lu H, Forbes RA and Verma A: Hypoxia-inducible factor 1 activation by aerobic glycolysis implicates the Warburg effect in carcinogenesis. J Biol Chem 277: 23111-23115, 2002.

27. Montagner M, Enzo E, Forcato M, Zanconato F, Parenti A, Rampazzo E, Basso G, Leo G, Rosato A, Bicciato S, et al: SHARP1 suppresses breast cancer metastasis by promoting degradation of hypoxia-inducible factors. Nature 487: 380-384, 2012.

28. Bertout JA, Patel SA and Simon MC: The impact of $\mathrm{O}_{2}$ availability on human cancer. Nat Rev Cancer 8: 967-975, 2008.

29. Chen M, Towers LN and O'Connor KL: LPA2 (EDG4) mediates Rho-dependent chemotaxis with lower efficacy than LPA1 (EDG2) in breast carcinoma cells. Am J Physiol Cell Physiol 292: C1927-C1933, 2007. 